\title{
Pyrimidine analogues in the treatment of experimental herpes infections
}

\author{
A. H. TOMLINSON \\ F. O. MacCallum \\ Public Health Laboratory and Virology Laboratory, Radcliffe Infirmary, Oxford
}

THE investigation of a new anti-microbial drug usually progresses from the test-tube to successful trials in animals followed by a cautious clinical appraisal, and the study of 5-iodo-2-deoxyuridine (IUdR), following this course, led to an accepted treatment for herpetic keratitis. In the treatment of the brain infections the order has been reversed and clinical use of pyrimidine analogues has preceded the accumulation of any satisfactory evidence from animal experiments. I propose to assess the evidence available in the literature and from our own work.

Two general matters should be clarified before turning to details. First the obvious, but frequently neglected point, that to be useful a drug must affect the course of an established infection and experiments in which the drug is given before, or at the same time, as the infecting virus, have little relevance. Second, the question of the 'blood-brain barrier' and whether it is permeable to pyrimidine analogues. Clarkson, Oppelt \& Byvoet (1967) studied the passage of IUdR from plasma to cerebrospinal fluid of dogs, but they ignored the tissue of the cerebrum in which the virus replicates. Even if given the knowledge that the drug does penetrate herpes infected brain, it would still be necessary to find out whether it influences the course of the disease. At the present, experimental results have to be interpreted without any direct information on the penetration of brain by iodo-deoxyuridine or cytosine-arabinoside.

\section{5-Iodo-2' -deoxyuridine (IUdR)}

The first reported animal experiment (Kaufman, 1962) demonstrated that IUdR was truly therapeutic for keratitis, i.e. it promoted healing of the cornea when applied 2 or 5 days after infection and many subsequent experiments have confirmed his results. In the course of such experiments Jawetz et al. (1965) made an observation which may have application to all treatment with IUdR. These workers found that the virus content of a rabbit cornea after 4 days' treatment was between 0.1 and 0.001 of that of control corneas, but when treatment stopped after 7 days the virus content rose above that of the controls on that day, finally falling to an undetectable amount 1 or 2 days later.
In a study of IUdR therapy of dermal herpes in guinea-pigs, Tomlinson \& MacCallum (1968) treated the animals, beginning $48 \mathrm{hr}$ after infection, with $120 \mathrm{mg} / \mathrm{kg}$, subcutaneously for 5 days. Of twelve lesions assayed at the end of treatment two contained no virus and the content of the others ranged from 10 to $10^{3}$ TCD. This finding, like that of Jawetz et al. (1965), suggests that treatment with IUdR is not alone sufficient to eliminate herpes virus from a lesion, and host defences must also operate.

Kaufman (1963) reported briefly, without technical details, that intrathecal IUdR did not prevent rabbits from developing encephalitis when the cornea was infected with a neurotropic strain of herpes simplex virus. $\mathrm{He}$ also said that intraperitoneal IUdR did not reduce the death-rate of mice infected intracerebrally. As the dose of drug was not stated, the significance of that work cannot be assessed.

In an experiment with six guinea-pigs infected intracerebrally with $10^{5.6} \mathrm{PFU}$ of virus, Tokumaru (1967) had four survivors following treatment with IUdR $100 \mathrm{mg} / \mathrm{kg}$ for 5 days whereas all control animals died.

In our own experiments (Tomlinson \& MacCallum, 1970) guinea-pigs were infected intracerebrally with $10,10^{2}$ or $10^{4}$ TCD of herpes simplex virus, which had been maintained by passage in mouse brain. Time of death of the control animals varied little with the infecting dose. Groups of four pigs were treated by injecting a $0.5 \%$ solution of IUdR intraperitoneally to give each day: either a single dose of $100 \mathrm{IUdR} \mathrm{mg} / \mathrm{kg}$; or three doses of $33 \mathrm{mg} / \mathrm{kg}$; or three doses of $100 \mathrm{mg} / \mathrm{kg}$. All pigs were treated for 5 days, different groups starting 1, 2 or 4 days after infection. The number of animals was too small to demonstrate a difference between the treatment schedules, so the results (Table 1) are grouped by day of starting treatment. All untreated animals died on or before the seventh day. Of thirtytwo treated pigs six survived and seventeen lived longer than the controls, but the six survivors were each on a different treatment schedule.

These results show that IUdR was therapeutic even when given on day 4 to pigs expected to die on days 5-7 and we may deduce that the drug penetrated 
TABLE 1. Guinea-pigs infected intracerebrally and treated with intraperitoneal IUdR

\begin{tabular}{lcccc}
\hline \multirow{2}{*}{$\begin{array}{l}\text { No. of } \\
\text { animals }\end{array}$} & $\begin{array}{c}\text { Treated** } \\
\text { on day }\end{array}$ & Range & Mean & Survivors \\
\cline { 3 - 4 } & 1 & $8-11$ & $9 \cdot 1$ & 1 \\
8 & 2 & $7-12$ & $9 \cdot 1$ & 2 \\
$12 \dagger$ & 4 & $5-12$ & $7 \cdot 0$ & 3 \\
$2 \dagger$ & Untreated & $5-7$ & $5 \cdot 8$ & 0 \\
\hline
\end{tabular}

*Dosage: see text.

†Three groups of four animals on different treatment schedules.

the blood-brain barrier. The effect was erratic and in no dosage-schedule/start-of-treatment group did more than one pig out of four survive.

\section{1- $\beta$-D-arabinofuranosylcytosine (cytarabine)}

A solution of cytarabine was shown by Underwood (1962) to be effective against herpes virus in the rabbit eye. Kaufman \& Moloney (1963) extended the observations to show that cytarabine was as effective as IUdR at the same weight/volume concentrate but slightly less effective at equal molarities.

Evidence for the activity of cytarabine on herpes virus in the brain is, however, scanty. Renis, Hollowell \& Underwood (1967) infected mice intracerebrally with $40 \mathrm{LD}_{50}$ of herpes simplex virus and $3 \mathrm{hr}$ later injected $0.9 \mathrm{mg}$ of cytarabine into the brain. This treatment either prolonged life or increased the number of survivors (it is not clear from the text which occurred) and either way the effect was prophylactic rather than therapeutic.

Hall (1968) infected rabbit eyes with a strain of herpes which produced neurological symptoms in 11 days and death from encephalitis in 21 days. Animals treated with an unspecified dose of cytarabine, which was said to be too high and to be toxic, showed no 'evidence of herpes simplex'.

We have tried to demonstrate an effect on herpes encephalitis in guinea-pigs. Some animals were infected intracerebrally, and, in an attempt to produce a less fulminating encephalitis, some were infected on the skin of the back or of the orbital region whence the virus travelled naturally to the brain. From the available evidence it seemed that $5 \mathrm{mg} / \mathrm{kg} /$ day for 5 days was the maximum dose likely to be given to a human patient, so this amount and $10 \mathrm{mg} / \mathrm{kg}$ were the doses used-the latter in the hope of demonstrating an antiviral effect even at the cost of some toxicity. The cytarabine was given intraperitoneally or, in one experiment, by intracardiac injection. From fifty-two animals, in twelve groups with different combinations of route of infection and treatment schedule, there were no survivors and in no group was the mean time to death significantly longer than in the appropriate control group. After
5 days treatment with $10 \mathrm{mg} / \mathrm{kg}$ by intracardiac injection the brains of six animals had a mean virus content of $10^{6} \mathrm{TCD}-$ no less than that of control animals. The dose cannot be increased as even 10 $\mathrm{mg} / \mathrm{kg}$ was toxic.

We conclude that cytarabine is either rapidly deaminated in the guinea-pig as in the mouse, or it is without effect on herpes encephalitis.

\section{9- $\beta$-D-arabinofuranosyl-adenine (adenine arabino- side)}

This compound was first synthesized as a potential anticancer drug and was then shown by Privat de Garilhe \& de Rudder (1964) to inhibit the multiplication of herpes and vaccinia viruses in tissue cultures. Further studies in vitro by Miller et al. (1968) showed that adenine arabinoside was at equal concentrations about as potent as IUdR in a plaquereduction test.

Adenine arabinoside is only slightly soluble in water $-0.05 \%$ at $25^{\circ} \mathrm{C}$ and $0.18 \%$ at $37^{\circ} \mathrm{C}$, as compared with the $0.5 \%$ concentration of IUdR which can be achieved at pH 8.5-9.0. In most of the animal experiments discussed below, the drug was administered as a suspension of fine particles and it is not clear what proportion did dissolve in body fluids and what remained undissolved and ineffective. Using such suspensions the acute oral toxicity for mice was found to be greater than $7950 \mathrm{mg} / \mathrm{kg}$ and the $\mathrm{LD}_{\mathbf{5 0}}$ for a single intraperitoneal injection 4700 $\mathrm{mg} / \mathrm{kg}$, death being due to peritonitis (Kurtz et al., 1968). When the drug was included in the diet for 28 days mice with a daily intake of $465 \mathrm{mg}$ or more per kg suffered liver damage and irreversible weight loss, but at lower doses weight was regained when the drug was withdrawn. It would appear, therefore, that the drug is much less toxic than IUdR or cytarabine.

To test the in vivo activity of adenine arabinoside, Sidwell et al. (1968) used hamsters infected on the cornea with a strain of virus which produced signs of encephalitis in 3-4 days and death in 9 days. An ointment containing $33 \%$, or greater, of adenine arabinoside significantly increased the number of survivors, but, because the drug was first applied only $4 \mathrm{hr}$ after infection, its use was more prophylactic than therapeutic.

In the treatment of mice infected intracerebrally with $32 L^{L} D_{50}$ of herpes virus adenine arabinoside was remarkably effective. Starting $24 \mathrm{hr}$ after infection, seven daily intraperitoneal doses of 1000 $\mathrm{mg} / \mathrm{kg}$ saved $50 \%$ of the mice; with twice daily oral doses of $1250 \mathrm{mg} / \mathrm{kg}$ for 4 days $60 \%$ survived. Treatment with a total of $2000-4000 \mathrm{mg} / \mathrm{kg}$ in several subcutaneous injections during the course of a single day also saved $50-70 \%$ of the mice (Sloan et al., 1968). They also showed that hypoxanthine arabinoside, to which adenine arabinoside is degraded in the 
body, was as active as the drug. Few results were presented for treatment initiated more than $24 \mathrm{hr}$ after infection.

In the doses given adenine arabinoside was effective, but the injection of large amounts of solid material intraperitoneally, or even subcutaneously, is not suitable for human patients, and given in true solution adenine arabinoside would present an even greater fluid load than does IUdR therapy. To find a suitable presentation of this drug appears to be a major problem.

Our own experiments with adenine arabinoside are only beginning and I have nothing to add.

For several reasons the performance of a drug in an animal model is not necessarily a guide to its effectiveness in human disease. Herpes simplex virus is not a natural parasite of mice, guinea-pigs or rabbits and it usually produces more serious disease in them than in man. The metabolism and excretion of the drugs may be different in animals and man. Lastly, in a serious disease like encephalitis supportive therapy and good nursing have an important role, but these cannot be given to animals.

The conclusion is that from the published evidence of animal models the case for chemotherapy of herpes encephalitis is, at best, 'not proven'.

\section{References}

Clarkson, D. R., Oppelt, W. W. \& Byvoet, P. (1967) The fate of 5-iodo-2-deoxyuridine (IUdR) in plasma and cerebrospinal fluid of dogs. Journal of Pharmacology and Experimental Therapeutics, 157, 581.

Hall T. C. (1968) Discussion. 1 Cytosin-ArabinosidSymposium, (Ed. by S. Witte, and R. K. Zahn), p. 180. Arzneimittel-Forschung, 19 Beiheft, Editio Cantor K.G. Aulendorf $\mathrm{i}$ Württ.

Jawetz, E., Schultz, R., Coleman, V. \& Okumoto, M. (1965) Studies on herpes simplex. XI. The antiviral dynamics of 5-iodo-2-deoxyuridine in vivo. Journal of Immunology, 95, 635.

Kaufman, H. E. (1962) Clinical cure of herpes simplex keratitis by 5-iodo-2-deoxyuridine. Proceedings of the Society for Experimental Biology and Medicine, 109. 251.
Kaufman, H. E. (1963) Chemotherapy of virus disease. Chemotherapia, 7, 1,

Kaufman, H. E. \& Maloney, E. D. (1963) IDU and cytosine arabinoside in experimental keratitis. Archives of Ophthalmology, 69, 626.

Kurtz, S. M., Fisken, R. A., Kaump, D. H. \& Schardein, J. L. (1968) Toxicity of 9- $\beta$-D-Arabinofuranosyladenine in mice and rabbits. Antimicrobial Agents and Chemotherapy $-1968,180$.

Miller, F. A., Dixon, G. J., Ehrlich, J., Sloan, B. J. \& MCLEAN, I. W. (1968) Antiviral activity of 9- $\beta$-D-Arabinofuranosyladenine. I. Cell culture studies. Antimicrobial Agents and Chemotherapy-1968, 136.

Privat de Garilhe, M. \& de Rudder, J. (1964) Effet de deux nucleosides de l'arabinose sur la multiplication des virus de l'herpes et de la vaccine en culture cellulaire. Compte rendu hebdomadaire des séances de l'Académie des sciences, 259, 2725.

Renis, H. E., Hollowell, C. A. \& Underwood, G. E. (1967) Nucleic Acids. III. Antiviral activity of nucleotides and dinucleoside phosphates containing ara-cytidine. Journal of Medicinal Chemistry, 10, 777.

Sidwell, R. W., Dixon, G. J., Schabel, F. M. \& Kaump, D. H. (1968) Antiviral activity of 9- $\beta$-D-arabinofuranosyladenine. II. Activity against herpes simplex keratitis in hamsters. Antimicrobial Agents and Chemotherapy-1968, 148.

Sloan, B. J., Miller, F. A., Ehrlich, J., Maclean, I. W. \& MACHAMER, H. E. (1968) Antiviral activity of 9- $\beta-D-$ arabinofuranosyladenine. IV. Activity against intracerebral herpes simplex virus infections in mice. Antimicrobial Agents and Chemotherapy-1968, 161.

Tokumaru, T. (1967) The protective effect of different immunoglobulins against herpetic encephalitis and skin infection in guinea pigs. Archiv für die Gesamte Virus forschung, 22, 332.

Tomlinson, A. H. \& MacCallum, F. O. (1968) The effect of 5-iodo-2-deoxyuridine on herpes simplex virus infections in guinea-pig skin. British Journal of Experimental Pathology, 49, 277.

Tomlinson A. H. \& MacCallum, F. O. (1970) The effect of iodo-deoxyuridine orpes simplex encephalitis in animals and man. Annals of the New York Academy of Sciences, 173, 20.

UNDER wooD, G. E. (1962) Activity of 1- $\beta$-D-arabinofuranosylcytosine hydrochloride against herpes simplex keratitis. Proceedings of the Society for Experimental Biology and Medicine, 111, 660. 